\title{
The testing for COVID-19 in symptomatic patients as a protective factor against stress, anxiety, and depression
}

Alan Chaves dos Santos 1

https://orcid.org/0000-0001-8614-4301

Paula Jaeger Tenório 2

iD https://orcid.org/0000-0002-4007-1562

Elias Almeida S. Barbosa 3

https://orcid.org/0000-0003-2118-071X

Gustavo Fonseca de Albuquerque Souza 4

https://orcid.org/0000-0002-1794-701X

Gabriela Albuquerque Souza 5

https://orcid.org/0000-0002-3631-6782
Gabriella de Almeida Figueredo Praciano 6

(iD) https://orcid.org/0000-0002-9746-8536

Laura Brito Barreto Maranhão 7

iD https://orcid.org/0000-0003-0009-3860

Gabriela Oliveira Lobo Pereira da Costa 8

(iD) https://orcid.org/0000-0002-1117-6816

Alex Sandro Rolland Souza 9

iD https://orcid.org/0000-0001-7039-2052

1,2,9 Departamento de Pós-graduação em Saúde Integral. Instituto de Medicina Integral Prof. Fernando Figueira. (IMIP), Recife, PE, Brasil. Rua dos Coelhos, 300. Boa Vista. E-mail: gugavolante@gmail.com

3 Centro de Biociência. Universidade Federal de Pernambuco (UFPE). Recife, PE, Brasil.

4,5,6,7 Faculdade de Medicina. Universidade Católica de Pernambuco (UNICAP). Recife, PE, Brazil.

8 Faculdade de Medicina. Faculdade Maurício de Nassau (UNINASSAU). Recife, PE, Brasil.

\section{Abstract}

Objectives: to determine the frequency of stress, anxiety, and depression symptoms in symptomatic patients for COVID-19. To evaluate the associated factors involved in these variants.

Methods: between May/June of 2020, it was conducted a prospective cross-section study with symptomatic participants for COVID-19 $(n=300)$. It was applied an online questionnaire and the DASS-21 to evaluate the mental health of participants.

Results: it was observed that 28.6\%, 29.7\% and 27\% of the participants showed severe/extreme levels symptoms of stress, anxiety, and depression, respectively. The testing for COVID-19 application had constituted a protective factor for the development of psychiatric morbidity, once it had shown significant association in the low frequencies of severe/extreme depression $[\mathrm{Odds}$ Ratio $(O R)]=0.26 ; p=0.002)$ and stress $(O R=0.39$; $p=0.01)$.

Conclusion: individuals that are symptomatic for COVID-19 are a vulnerable group that may present high symptomatology for depression, anxiety, and stress. The identification of psychiatric morbidity frequency and its associated factors may contribute for the development of mental health strategies aiming at the prevention and mitigation of psychological impact in COVID-19 symptomatic population during the pandemic.

Key words COVID-19, Depression, Anxiety, Stress psychological, Social isolation

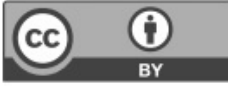

This article is published in Open Access under the Creative Commons Attribution license, which allows use, distribution, and reproduction in any medium, without restrictions, as long as the original work is correctly cited. http://dx.doi.org/10.1590/1806-9304202100\$100007 


\section{Introduction}

The World Health Organization (WHO) had officially declared a pandemic on March 11, 2020 caused by the SARS-CoV-2. ${ }^{1}$ In addition, the current absence of an efficient treatment or a vaccine against the virus made the WHO recommend to all countries the adoption of restrictive social measures allied to environmental and hand sanitization, thereby the quickly spread of the COVID-19 can be stopped and its damages, minimized. ${ }^{1}$

The measures encountered to contain virus transmissibility include, among others: social distancing, applied to the general population; social isolation, applied to infected individuals, and quarantine, applied when there is a possibility of exposition to the SARS-CoV-2.2 These restrictive measures affect the gregarious nature of human beings, which have the necessity to live collectively and to interact with their pairs; 3 this may produce a significant psychological distress, leading to acute stress and feelings as boredom, loneliness, anger and insecurity. $2,4 \mathrm{In}$ general, studies who evaluate the emotional impact in the context of COVID-19 pandemic, have identified in the general population, feelings of hopelessness, helplessness, stigmas, guilty and deep loss of life proposal.5,6 The COVID-19 pandemic has been considered, not only an epidemiological crisis, but also a psychological 7 and social 5 crisis. The absence of an effective treatment, and the worldwide propagation of the virus in addition to the financial, routine and life losses have contributed to the arising of psychiatric morbidity as stress, anxiety, and depression. ${ }^{8}$ It is also observed the increasing of suicide cases, ${ }^{9}$ as well as the increase of health risk behaviors, such as alcohol and tobacco consumption. ${ }^{10}$ Even the infection symptoms, such as fever, hypoxia and cough are associated with an increase of the vigilance state and aggravation of anxiety and panic disorder. ${ }^{11}$ In some cases, the anxiety related to the absence of information about the health state and the need of frequent body temperature checking and hand sanitization were associated with the development or intensification of compulsive-obsessive symptoms. ${ }^{12,13}$

Despite some countries that have already controlled the COVID-19 crisis, the pandemic has seriously affected the Americas, where the number of new cases and deaths increases daily. One of the most affected countries is Brazil, who must deal with the sub-notification of cases and deaths, due to the shortage of COVID-19 diagnostic tests. ${ }^{14,15}$

The WHO recommends that all suspected cases, symptomatic or non-symptomatic, must be tested by collecting samples of naso-pharyngeal and oropharyngeal swabs and followed by RT-PCR analysis. ${ }^{14}$ However, the testing protocols in Brazil did not attend this recommendation until June 24th, when Brazil's Health Ministry determined the testing for any individual with influenza-like symptoms. ${ }^{15}$ Before this, the orientation was to test only severe cases, and in some states, also healthcare and essential workers. ${ }^{16}$

Based on all the facts exposed above, the present study aimed to investigate the factors associated with psychic symptoms in symptomatic patients for COVID-19, seeking at the prevention of these mental disorders. Therefore, our hypothesis was that taking a COVID-19 test by symptomatic patients would diminish the frequency of signs and symptoms for depression, anxiety, and stress in symptomatic patients for COVID- 19 .

\section{Methods}

This was a prospective cross-section study conducted via an online questionnaire, in which participants from different regions of Brazil were assessed. It included Brazilians with more than 18 years of age and symptomatic for COVID-19, thereby it excluded participants who answered the questions incorrectly or in duplicates, and participants who were asymptomatic for COVID-19.The patients were considered symptomatic when the participants showed any influenza-like symptoms, thus considering as a suspect case for COVID-19, such as fever, cough, nasal congestion, coryza, sore throat, anosmia, dysgeusia, ageusia, myalgia, body aches and chills

An invitation was sent to the participants by email or social media (e.g.: Instagram, Twitter, Facebook and Whatsapp), requesting for them to forward to contacts, according to the snowball sampling technique. The study data were collected using Google Forms in which objective and easy-tounderstand questions were added to the survey. The instrument was previously tested after conducting a pilot study and the average response of the participants was 7 minutes. During the process of filling out the forms, participants were asked to answer questions related to their mental health, habits and social demographic status that were affected or not by the COVID-19 pandemic and social distancing and isolation measures.

The dependents variables were stress, anxiety, and depression. The independent variables studied were biological ones, such as age and sex, and the social demographic ones were color/race, education 
level, marital status (partner), number of children, number of houserooms and religion.

It was also questioned about the leisure activities performed by the participants, such as physical exercises before and during the social distancing period. This study had also searched for prior diagnosis of anxiety and depression, chronic diseases, alcoholism, and usage of sleep medication. When related to job activities, we focused on the practice of remote activities, occupation field, and monthly income before and during the social distancing period.

In addition, it was asked a few questions about the measures that have been taken to prevent SARSCoV-2 infection, such as whether the person is on social distancing or not, if there is history of contact with any COVID-19 suspected or confirmed case, and if it was taken a COVID-19 molecular or serological test. The social distancing was defined as a community contention measure adopted to prevent SARS-CoV-2 dissemination. 17

To evaluate the mental health state of the symptomatic population for COVID-19, it was used the Depression Anxiety Stress Scales- Short Form (DASS-21). This scale was developed by Lovibond and Lovibond, 18 adapted and validated to Brazil standard by Vignola and Tucci19 and Patias et al.20 The DASS-21 is a Likert like instrument with 4 main points, which participants evaluate each symptom that has been described in the enlisted items in agreement to the last week (the previous week). In the instrument, the answers vary from 0 (did not applied to me at all), 1 (applied to me in some degree or for short time), 2 (applied to me in a considerable degree or a good part of time) to 3 (applied to me very much or most of the time). 19

The scores for depression, anxiety and stress are determined by summing the 21 items altogether. The DASS-2 1 also classified the severity of the symptoms considering scores ranges as normal, mild, moderate, severe, or extreme. 18 The stress subscale is composed by questions $1,6,8,11,12,14$, and 18 , that describes normal symptoms (if scored between $0-14)$, mild signs and symptoms (15-18), moderate (19-25), severe (26-33) and extreme (>33). Similar to that, the anxiety subscale is composed by the questions $2,4,7,9,15,19$ and 20 , that describes normal symptoms (if scored between 0-7), mild signs and symptoms (8-9) moderate (10-14), severe $(15-19)$ and extreme (>19). Following this pattern, the depression subscale is composed by questions 3 , $5,10,13,16,17$ and 21 , that describes normal symptoms (if scored between 0-9), mild signs and symptoms (10-13), moderate (14-20), severe (21-27) and extreme $(>27) .19$

A database was created to submit the data collected to cleaning and consistency tests, in which variables were obtained and data errors were corrected. After these primary data treatments, the data have proceeded to a data analysis.

The analysis was conducted using Epiinfo 3.5.1 version (Centers for Disease Control and Prevention - CDC, United States of America - USA, Atlanta, DC). First, a univariate analysis was conducted to describe the distribution of the dependent and independent variables in the study population, using the chi squared test or Fisher's exact test, when relevant. The prevalence ratio and their respective $95 \%$ confidence intervals (CI95\%) were calculated. In the multivariate analysis, the initial model consisted of explanatory variables with $p$-values $<0.20$ in the univariate analysis, and it were also calculated the Odds ratio (OR) and its 95\% confidence interval. The variables with significance level $<0.05$ remained in the final model.

Before all participants filled out the questionnaire, it was given an online consent in the first section, which required a virtual signature of the participants, so they could continue to fill out the online survey. Moreover, this study has been approved by the Human Research Ethics Committee of the Institute of Integrative Medicine Prof. Fernando Figueira (IMIP - Portuguese acronym) and Catholic University of Pernambuco (UNICAP Portuguese acronym). The respective Certificate of Presentation for Ethical Appreciation are 30623020.1.3001.5201 and 30623020.1.0000.5206.

\section{Results}

It was obtained 3,765 answers, although answers from 565 individuals who did not answer the questionnaire completely or who had answered it in duplicate were excluded. Additionally, 3,465 answers from asymptomatic individuals were also excluded, remaining 300 participants, who were assessed. Of these, the mean age was $33.0 \pm 11.6$ years, ranging from 18 to 78 years.

The frequency of signs and symptoms of stress, anxiety, and depression in COVID-19 symptomatic participants $(\mathrm{n}=300)$, according to the symptomatology scale was calculated. Concerning the stress subscale, $122(40.7 \%)$ participants were considered as normal, $40(13.3 \%)$ mild, $52(17.3 \%)$ moderate and $86(28.6 \%)$ severe or extreme. The anxiety subscale revealed that $111(37 \%)$ participants were considered as normal, $23(7.7 \%)$ mild, $77(25.7 \%)$ moderate and $89(29.7 \%)$ severe or extreme. 
Regarding the depression subscale, 111 (37\%) participants were normal, 44 (14.7\%) mild, 64 $(21.3 \%)$ moderate and $81(27 \%)$ were evaluated as severe or extreme cases of depression (Table 1). Table 2, Table 3 and Table 4 report the results of univariate analyses of the association between the studied variables and severe/extreme symptoms of stress, anxiety and depression, respectively.

In respect to the presence of sign and symptoms of severe/extreme stress, it was observed after a multivariate analysis, an expressive association with the female sex $(\mathrm{OR}=2.18$; CI95\%=1.02-4.65), not having children $(\mathrm{OR}=3.27$; $\mathrm{CI} 95 \%=1.69-6.35)$, less than 3 rooms in the house $(\mathrm{OR}=2.97$; CI95\% $=1.15$ 7.66), maintaining, starting or increasing the usage of sleep medication $(\mathrm{OR}=3.22$; $\mathrm{CI} 95 \%=1.69-6.13)$, anxiety and depression antecedents $(\mathrm{OR}=2.03$; $\mathrm{CI95 \%}=1.04-3.96)$, reducing or not practicing leisure activities $(\mathrm{OR}=2.76$; $\mathrm{CI} 95 \%=1.23-6.17)$ and taking the COVID-19 test $(\mathrm{OR}=0.39$; CI95\% $=0.18$ 0.82) (Table 2).

Regarding anxiety, it is noted that signs and symptoms of severe/extreme anxiety showed a significant association, through multivariate

Table 1

Stress, anxiety, and depression prevalence, following the severity levels of symptomatic patients for COVID-19.

\begin{tabular}{lcccccccccc}
\hline \multirow{2}{*}{ Variables } & \multicolumn{2}{c}{ Normal } & \multicolumn{2}{c}{ Mild } & \multicolumn{2}{c}{ Moderate } & \multicolumn{2}{c}{ Severe } & \multicolumn{2}{c}{ Extreme } \\
\cline { 2 - 12 } & $\mathrm{n}$ & $\%$ & $\mathrm{n}$ & $\%$ & $\mathrm{n}$ & $\%$ & $\mathrm{n}$ & $\%$ & $\mathrm{n}$ & $\%$ \\
\hline Stress & 122 & 40.7 & 40 & 13.3 & 52 & 17.3 & 52 & 17.3 & 34 & 11.3 \\
Anxiety & 111 & 37.0 & 23 & 7.7 & 77 & 25.7 & 33 & 11.0 & 56 & 18.7 \\
Depression & 111 & 37.0 & 44 & 14.7 & 64 & 21.3 & 31 & 10.3 & 50 & 16.7 \\
& & & & & & & & & &
\end{tabular}

Table 2

\begin{tabular}{|c|c|c|c|c|c|c|c|c|}
\hline \multirow[t]{2}{*}{ Variables } & \multirow[t]{2}{*}{$\mathbf{N}$} & \multirow[t]{2}{*}{$\%$} & \multicolumn{3}{|c|}{ Initiation Model } & \multicolumn{3}{|c|}{ Final Model } \\
\hline & & & OR & $\mathrm{Cl} 95 \%$ & $p$ & OR & Cl95\% & $p$ \\
\hline \multicolumn{9}{|l|}{ Age (years) } \\
\hline$\leq 44$ & 80 & 32.5 & 1.44 & $0.49-4.16$ & 0.5 & & & \\
\hline$>44$ & 6 & 11.1 & 1.0 & & & & & \\
\hline Feminine sex & & & & & & 2.18 & $1.02-4.65$ & 0.04 \\
\hline Yes & 70 & 30.4 & 2.22 & $1.01-4.88$ & 0.04 & & & \\
\hline No & 14 & 20.6 & 1.0 & & & & & \\
\hline \multicolumn{9}{|l|}{ Religion } \\
\hline Yes & 35 & 38.9 & 1.0 & & & & & \\
\hline No & 51 & 24.3 & 1.87 & $0.94-3.70$ & 0.07 & & & \\
\hline \multicolumn{9}{|l|}{ Monthly income } \\
\hline Reduced & 47 & 32.9 & 1.76 & $0.96-3.25$ & 0.06 & & & \\
\hline Maintained/Increased & 39 & 24.8 & 1.0 & & & & & \\
\hline \multicolumn{9}{|l|}{ Partner } \\
\hline Yes & 57 & 33.9 & 1.0 & & & & & \\
\hline No & 29 & 22.0 & 1.05 & $0.49-2.24$ & 0.89 & & & \\
\hline \multicolumn{9}{|l|}{ Children } \\
\hline Yes & 66 & 38.8 & 1.0 & & & & & \\
\hline No & 20 & 15.4 & 3.12 & $1.35-7.22$ & 0.007 & 3.27 & $1.69-6.35$ & $<0.001$ \\
\hline \multicolumn{9}{|l|}{ Rooms in the house } \\
\hline $1-3$ & 13 & 44.8 & 2.47 & $0.92-6.64$ & 0.07 & 2.97 & $1.15-7.66$ & 0.02 \\
\hline \multirow[t]{2}{*}{$>3$} & 73 & 26.9 & 1.0 & & & & & \\
\hline & & & & & & & & continue \\
\hline
\end{tabular}

Variables $p>0.20$ in univariate analysis, which did not enter the multivariate model: chronic diseases, history of contact with a suspected case of COVID-19, healthcare worker, education level, ethnicity and consumption of alcoholic beverages. 


\begin{tabular}{|c|c|c|c|c|c|c|c|c|}
\hline \multirow[t]{2}{*}{ Variables } & \multirow[t]{2}{*}{$\mathbf{N}$} & \multirow[t]{2}{*}{$\%$} & \multicolumn{3}{|c|}{ Initiation Model } & \multicolumn{3}{|c|}{ Final Model } \\
\hline & & & OR & $\mathrm{Cl} 95 \%$ & $p$ & OR & $\mathrm{Cl} 95 \%$ & $p$ \\
\hline \multicolumn{9}{|l|}{ Anxiety and depression antecedent } \\
\hline Yes & 62 & 40.0 & 2.11 & $1.05-4.22$ & 0.03 & 2.03 & $1.04-3.96$ & 0.03 \\
\hline No & 24 & 16.6 & 1.0 & & & & & \\
\hline \multicolumn{9}{|l|}{ Usage of sleep medication } \\
\hline Maintained/Started/Increased & 50 & 45.4 & 3.32 & $1.69-6.50$ & $<0.001$ & 3.22 & $1.69-6.13$ & $<0.001$ \\
\hline Reduced/No usage & 36 & 19.0 & 1.0 & & & & & \\
\hline \multicolumn{9}{|l|}{ Remote work or education } \\
\hline Yes & 33 & 37.5 & 1.0 & & & & & \\
\hline No & 53 & 25.0 & 1.19 & $0.62-2.30$ & 0.58 & & & \\
\hline \multicolumn{9}{|l|}{ Physical exercises } \\
\hline Maintained/Started/Increased & 23 & 23.2 & 1.0 & & & & & \\
\hline Reduced/No practice & 63 & 31.3 & 1.56 & $0.79-3.07$ & 0.19 & & & \\
\hline \multicolumn{9}{|l|}{ Leisure activities } \\
\hline Maintained/Started/Increased & 18 & 47.4 & 1.0 & & & & & \\
\hline Reduced/No practice & 68 & 26.0 & 2.6 & $1.09-6.17$ & 0.02 & 2.76 & $1.23-6.17$ & 0.01 \\
\hline \multicolumn{9}{|l|}{ COVID-19 test } \\
\hline Yes & 16 & 16.7 & 0.5 & $0.22-1.13$ & 0.09 & 0.39 & $0.18-0.82$ & 0.01 \\
\hline No & 86 & 34.3 & & & & & & \\
\hline \multicolumn{9}{|l|}{ Social Distancing practices } \\
\hline Yes & 80 & 31.6 & 2.29 & $0.83-6.34$ & 0.1 & & & \\
\hline No & 6 & 12.8 & 1.0 & & & & & \\
\hline
\end{tabular}

Variables $p>0.20$ in univariate analysis, which did not enter the multivariate model: chronic diseases, history of contact with a suspected case of COVID-19, healthcare worker, education level, ethnicity and consumption of alcoholic beverages.

\section{Table 3}

\begin{tabular}{|c|c|c|c|c|c|c|c|c|}
\hline \multirow[t]{2}{*}{ Variables } & \multirow[t]{2}{*}{$\mathbf{N}$} & \multirow[t]{2}{*}{$\%$} & \multicolumn{3}{|c|}{ Initiation Model } & \multicolumn{3}{|c|}{ Final Model } \\
\hline & & & OR & $\mathrm{Cl} 95 \%$ & $p$ & OR & $\mathrm{Cl} 195 \%$ & $p$ \\
\hline \multicolumn{9}{|l|}{ Age (years) } \\
\hline$\leq 44$ & 78 & 31.7 & 0.95 & $0.36-2.54$ & 0.93 & & & \\
\hline$>44$ & 11 & 20.4 & 1.0 & & & & & \\
\hline \multicolumn{9}{|l|}{ Monthly income } \\
\hline Reduced & 51 & 35.6 & 2.43 & $1.31-4.49$ & 0.004 & 2.39 & $1.32-4.32$ & 0.003 \\
\hline Maintained/Increased & 38 & 24.2 & 1.0 & & & & & \\
\hline \multicolumn{9}{|l|}{ Partner } \\
\hline Yes & 58 & 34.5 & 1.0 & & & & & \\
\hline No & 31 & 23.5 & 1.52 & $0.71-3.21$ & 0.27 & & & \\
\hline \multicolumn{9}{|l|}{ Religion } \\
\hline Yes & 38 & 42.5 & 1.0 & & & & & \\
\hline No & 51 & 24.3 & 2.42 & $1.22-4.78$ & 0.01 & 2.61 & $1.39-4.89$ & 0.002 \\
\hline \multicolumn{9}{|l|}{ Children } \\
\hline Yes & 64 & 37.7 & 1.0 & & & & & \\
\hline No & 25 & 19.2 & 2.13 & $0.94-4.86$ & 0.06 & 3.17 & $1.70-5.94$ & $<0.001$ \\
\hline \multicolumn{9}{|l|}{ Rooms in the house } \\
\hline $1-3$ & 14 & 48.3 & 2.50 & $0.89-7.05$ & 0.08 & & & \\
\hline$>3$ & 75 & 27.7 & 1.0 & & & & & \\
\hline
\end{tabular}

Variables $p>0.20$ in univariate analysis, which did not enter the multivariate model: healthcare worker, sex, level of education, ethnicity consumption of alcohol beverages and social distancing practices. 
Variables correlated to severe/extreme anxiety in symptomatic patients for COVID-19.

\begin{tabular}{|c|c|c|c|c|c|c|c|c|}
\hline \multirow[t]{2}{*}{ Variables } & \multirow[t]{2}{*}{$\mathbf{N}$} & \multirow[t]{2}{*}{$\%$} & \multicolumn{3}{|c|}{ Initiation Model } & \multicolumn{3}{|c|}{ Final Model } \\
\hline & & & OR & $\mathrm{Cl} 95 \%$ & $p$ & OR & $\mathrm{Cl} 195 \%$ & $p$ \\
\hline \multicolumn{9}{|l|}{ Anxiety and depression antecedent } \\
\hline Yes & 63 & 40.6 & 1.99 & $0.99-3.98$ & 0.05 & 2.15 & $1.12-4.11$ & 0.02 \\
\hline No & 26 & 17.9 & 1.0 & & & & & \\
\hline \multicolumn{9}{|l|}{ Chronic Diseases } \\
\hline Yes & 51 & 36.4 & 1.47 & $0.78-2.77$ & 0.23 & & & \\
\hline No & 38 & 23.8 & 1.0 & & & & & \\
\hline \multicolumn{9}{|l|}{ Remote work or education } \\
\hline Maintained/Started/Increased & 35 & 39.8 & 1.0 & & & & & \\
\hline Reduced/No usage & 54 & 25.5 & 1.64 & $0.85-3.15$ & 0.13 & & & \\
\hline \multicolumn{9}{|l|}{ Physical exercises } \\
\hline Maintained/Started/Increased & 26 & 26.3 & 1.0 & & & & & \\
\hline Reduced/No usage & 63 & 31.3 & 1.05 & $0.53-2.05$ & 0.87 & & & \\
\hline \multicolumn{9}{|l|}{ Usage of sleep medication } \\
\hline Maintained/Started/Increased & 52 & 47.3 & 3.94 & $2.01-7.73$ & $<0.001$ & 3.53 & $1.85-6.74$ & $<0.001$ \\
\hline Reduced/No usage & 37 & 19.5 & 1.0 & & & & & \\
\hline \multicolumn{9}{|l|}{ Leisure activities } \\
\hline Maintained/Started/Increased & 21 & 55.3 & 1.0 & & & & & \\
\hline Reduced/No usage & 68 & 26.0 & 4.28 & $1.79-10.19$ & 0.001 & 4.91 & $2.15-11.20$ & $<0.001$ \\
\hline \multicolumn{9}{|l|}{ COVID-19 test } \\
\hline Yes & 21 & 21.9 & 0.62 & $0.27-1.41$ & 0.26 & & & \\
\hline No & 68 & 33.3 & 1.0 & & & & & \\
\hline \multicolumn{9}{|l|}{ History of contact with a COVID-19 } \\
\hline \multicolumn{9}{|l|}{ suspected case } \\
\hline Yes & 66 & 33.7 & 2.78 & $1.39-5.54$ & 0.003 & 2.45 & $1.28-4.70$ & 0.006 \\
\hline No & 23 & 22.1 & 1.0 & & & & & \\
\hline
\end{tabular}

Variables $p>0.20$ in univariate analysis, which did not enter the multivariate model: healthcare worker, sex, level of education, ethnicity, consumption of alcohol beverages and social distancing practices.

Table 4

\begin{tabular}{|c|c|c|c|c|c|c|c|c|}
\hline \multirow[t]{2}{*}{ Variables } & \multirow[t]{2}{*}{$\mathbf{N}$} & \multirow[t]{2}{*}{$\%$} & \multicolumn{3}{|c|}{ Initiation Model } & \multicolumn{3}{|c|}{ Final Model } \\
\hline & & & OR & $\mathrm{Cl} 95 \%$ & $p$ & OR & $\mathrm{Cl} 95 \%$ & $p$ \\
\hline \multicolumn{9}{|l|}{ Age (years) } \\
\hline$\leq 44$ & 77 & 31.3 & 2.60 & $0.75-8.98$ & 0.13 & & & \\
\hline$>44$ & 4 & 7.4 & 1.0 & & & & & \\
\hline \multicolumn{9}{|l|}{ Education level } \\
\hline Graduation & 56 & 31.1 & 0.95 & $0.45-2.03$ & 0.91 & & & \\
\hline Post-graduation & 25 & 20.8 & 1.0 & & & & & \\
\hline \multicolumn{9}{|l|}{ Religion } \\
\hline Yes & 38 & 42.2 & 1.0 & & & & & \\
\hline No & 43 & 20.5 & 2.25 & $1.14-4.42$ & 0.02 & 2.28 & $1.19-4.36$ & 0.013 \\
\hline \multicolumn{9}{|l|}{ Partner } \\
\hline Yes & 58 & 34.5 & 1.0 & & & & & \\
\hline No & 23 & 17.4 & 1.63 & $0.72-3.68$ & 0.24 & & & \\
\hline \multicolumn{9}{|l|}{ Children } \\
\hline Yes & 63 & 37.1 & 1.0 & & & & & \\
\hline No & 18 & 13.8 & 2.78 & $1.14-6.75$ & 0.02 & 3.88 & $1.93-7.77$ & $\begin{array}{c}<0.001 \\
\text { continue }\end{array}$ \\
\hline
\end{tabular}

Variables $p>0.20$ in univariate analysis, which did not enter the multivariate model: Monthly income, sex, ethnicity, number of rooms in the house, remote work or education, consumption of alcoholic beverages and social distancing practices. 


\begin{tabular}{|c|c|c|c|c|c|c|c|c|}
\hline \multirow[t]{2}{*}{ Variables } & \multirow[t]{2}{*}{$\mathbf{N}$} & \multirow[t]{2}{*}{$\%$} & \multicolumn{3}{|c|}{ Initiation Model } & \multicolumn{3}{|c|}{ Final Model } \\
\hline & & & OR & $\mathrm{Cl} 95 \%$ & $p$ & OR & $\mathrm{Cl} 95 \%$ & $p$ \\
\hline \multicolumn{9}{|l|}{ Anxiety and depression Antecedent } \\
\hline Yes & 56 & 36.1 & 1.01 & $0.49-2.09$ & 0.96 & & & \\
\hline No & 25 & 17.2 & 1.0 & & & & & \\
\hline \multicolumn{9}{|l|}{ Chronic Diseases } \\
\hline Yes & 46 & 32.9 & 1.30 & $0.67-2.52$ & 0.42 & & & \\
\hline No & 35 & 21.9 & 1.0 & & & & & \\
\hline \multicolumn{9}{|l|}{ Healthcare Worker } \\
\hline Yes & 39 & 23.0 & 0.55 & $0.27-1.11$ & 0.09 & & & \\
\hline No & 42 & 32.1 & 1.0 & & & & & \\
\hline \multicolumn{9}{|l|}{ Usage of sleep medication } \\
\hline Maintained/Started/Increased & 48 & 43.6 & 6.14 & $2.92-12.89$ & $<0.001$ & 5.71 & $3.0-10.86$ & $<0.001$ \\
\hline Reduced/No usage & 33 & 17.4 & 1.0 & & & & & \\
\hline \multicolumn{9}{|l|}{ Physical Exercises } \\
\hline Maintained/Started/Increased & 17 & 17.2 & 1.0 & & & & & \\
\hline Reduced/No practice & 64 & 31.8 & 3.07 & $1.44-6.57$ & 0.004 & 2.62 & $1.27-5.38$ & 0.009 \\
\hline \multicolumn{9}{|l|}{ Leisure Activities } \\
\hline Maintained/Started/Increased & 18 & 47.4 & 3.59 & $1.42-9.06$ & 0.007 & 3.10 & $1.30-7.45$ & 0.011 \\
\hline Reduced/No practice & 63 & 24.1 & 1.0 & & & & & \\
\hline \multicolumn{9}{|l|}{ COVID-19 Test } \\
\hline Yes & 10 & 10.4 & 0.43 & $0.17-1.07$ & 0.07 & 0.26 & $0.11-0.61$ & 0.002 \\
\hline No & 71 & 34.8 & 1.0 & & & & & \\
\hline \multicolumn{9}{|l|}{ History of contact with a COVID-19 } \\
\hline \multicolumn{9}{|l|}{ suspected case } \\
\hline Yes & 45 & 23.0 & 0.76 & $0.38-1.52$ & 0.44 & & & \\
\hline No & 36 & 34.6 & 1.0 & & & & & \\
\hline
\end{tabular}

Variables $p>0.20$ in univariate analysis, which did not enter the multivariate model: Monthly income, sex, ethnicity, number of rooms in the house, remote work or education, consumption of alcoholic beverages and social distancing practices.

analysis, with decreased monthly income $(\mathrm{OR}=2.39$ $\mathrm{CI} 95 \%=1.32-4.32)$, absence of religion $(\mathrm{OR}=2.61$; CI95\% $=1.39-4.89)$, absence of children $(\mathrm{OR}=3.17$; $\mathrm{CI} 95 \%=1.70-5.94)$, anxiety and depression antecedents $(\mathrm{OR}=2.15$; $\mathrm{CI} 95 \%=1.12-4.11)$, usage of sleep medication $(\mathrm{OR}=3.53$; $\mathrm{CI} 95 \%=1.85-6.74)$, reducing or not practicing leisure activities $(\mathrm{OR}=$ 4.91; CI95\% $=2.15-11.20)$ and history of contact with suspected cases of COVID-19 $(\mathrm{OR}=2.45$; CI95\%= 1.28-4.70) (Table 3).

Signs and symptoms of severe/extreme depression showed, through multivariate analysis, association with the absence of religion $(\mathrm{OR}=2.28$; CI95\% $=1.19-4.36)$, absence of children $(\mathrm{OR}=3.88$; $\mathrm{CI} 95 \%=1.93-7.77)$, usage of sleep medication $(\mathrm{OR}=$ 5.71; $\mathrm{CI} 95 \%=3.0-10.86)$, reducing or not practicing physical exercises $(\mathrm{OR}=2.62 ; \mathrm{CI} 95 \%=1.27-5.38)$ and reducing or not practicing leisure activities $(\mathrm{OR}=3.10 ; \mathrm{CI} 95 \%=1.30-7.45)$. The test for COVID-19 showed a negative association, from which can be inferred that those who performed the test for COVID-19 had a lower frequency sign and symptoms of severe/extreme depression $(\mathrm{OR}=0.26$; CI95\% $=0.11-0.61)$ (Table 4).

\section{Discussion}

Although most of the population will not be infected by the SARS-CoV-2, the current global scenario has a traumatic potential,20,21 due to the multiple crisis that COVID-19 pandemic has proportionated. Differently from other virus outbreaks, the COVID19 pandemic has gained an enormous proportion upon real time and large-scale information sharing. The anxiety related to an uncertain future, to the absence of a vaccine and to the effects of adopted measures to prevent the disease's dissemination has contributed to the increase of psychic distress in general population. 4

The frequency of signs and symptoms of stress, 
anxiety, and depression obtained in our study was high, when compared to the frequency found in other countries. 22 According a meta-analysis, 22 the stress prevalence acquired from five studies $(n=9,075)$ corresponded to $29.6 \%$ of the sample. Whereas, the anxiety and depression prevalence, which had included 17 studies $(n=63,439)$ and 14 studies $(\mathrm{n}=44,531)$, corresponded to $31.9 \%$ and $33.7 \%$, respectively. These studies had considered any symptomatology level (mild, moderate, severe, or extreme).22 It is noted that this review included general population and our study was executed with a more susceptible population to develop mental disorders, since they are living with the possibility of being contaminated or not by the virus, which can be described as an anxiogenic and emotionally immobilizer situation.

However, the psychiatric morbidity frequency identified in the COVID-19 symptomatic population, in our study, is similar to studies that assessed general population, as it can be observed in the first study that evaluated the psychological impact in Chinese people during the beginning of the pandemic 23 and a study carried out in Turkey that analyzed a population with COVID-19 diagnosis. ${ }^{5}$ Wang et al. 23 noted that more than a half of the participants, $53.8 \%$, presented moderate to severe psychological impact upon the COVID-19 outbreak. The study also found that a bad state of health, evaluated by the participant, and the presence of physical symptomatology such as chills, myalgia, cough, sore throat and dizziness obtained a statistically significant association with high anxiety, stress and depression indexes. Therefore, this indicates that symptomatic patients are at risk to develop psychiatric morbidity. 23

Concerning the factors associated with the psychiatric morbidity evaluated, the result that have excelled in this study was the significant association between taking a COVID-19 test and the decrease of severe/extreme severe signs and symptoms of stress, anxiety, and depression. Few studies analyzed the association between performing a COVID-19 test and the presence of psychiatric morbidity. In a study realized with a non-contaminated population in Turkey, the results did not identify a significant association between depression levels and the action of take a COVID-19 test. ${ }^{5}$ However, in a research that assessed the COVID-19 testing in repatriated Europeans coming to France from Wuhan, China, it was noted that testing the repatriated constituted a minimizer factor to anxiety. 24 According to the authors, the rapid diagnosis, not only tranquilizes the tested group, but also may consist of a useful tool for managing the crisis and assist in decision making regarding the establishment of quarantine.24 Although the study focused on asymptomatic individuals, it contributes and corroborates the association between testing for COVID-19 and decreasing of the psychological impact on those tested.24 Similar to the previous study, 24 the present study also observed a decrease in levels of stress, anxiety and depression in those who tested for COVID-19, however our population consisted of symptomatic individuals. The study suggests that symptomatic individuals are likely to show signs of stress, anxiety and depression, ${ }^{11}$ probably due to fear of a possible disease complication. It was agreed, however, that COVID-19 test protects them against these risks, since the majority of symptomatic individuals who take the exam presents negative result.

The fear of being infected and of infecting other people is a normal reaction and allows individuals to avoid exposing themselves to risky situations and to adopt protective measures. 25 However, when fear becomes exacerbated, it can produce dysfunctional emotional reactions, activating and potentiating preexisting psychiatric disorders. ${ }^{26}$ It is likely that the COVID-19 test will bring a sense of tranquility to symptomatic and non-symptomatic individuals. When taking a COVID-19 test, the result confirming or discharging the diagnosis of the disease minimizes the fear of the unknown and allows the development of positive coping strategies, reducing the psychic distress and, consequently, decreasing the anxiety, depression and stress levels. The result of the test indicating that the individual has already been contaminated by the virus can also promote the feeling of security, which comes from the idea of an "immunity passport": the long-term immunity memory antibodies would act if the virus infects the person again, then not developing the COVID-19. It is worth noting that there are no conclusive studies that indicate a long-term immunity against the SARS-CoV-2.27

Regarding other studied variables, it was observed that the feminine gender has presented a significant association with severe/extreme of stress and anxiety. Further studies have also identified that women are more susceptible to develop stress and anxiety during the pandemic. $5,22,23$ Although the literature indicates that women presents higher risks to have depression than the opposite sex, ${ }^{28}$ in the present study it was not observed an association between the feminine gender and severe/extreme depression symptoms, then this variable was not assessed in the multivariate analysis. In India it was also not observed any significant difference in 
depression levels among men and women. ${ }^{29}$ The absence of children and partners was pointed out as a risk factor for developing severe/extreme stress, anxiety, and depression. It is noted that to be alone during the quarantine and isolation social period consists in a hazard that may contribute to the rise and/or aggravation of mental disorders. ${ }^{5}$ Young aged individuals were correlated to a high frequency of sign and symptoms of psychiatric morbidity, which corroborates other authors. $5,23,29$ This group of people is composed in its majority by students, a population that has one of the most affected daily routine and isolation restrictive measures due to the closure of schools and universities around the world. ${ }^{6}$ The difficulty to access on-line platforms of distance education in addition to the lack of internet are part of anxiogenic situations that are experienced by a portion of economically disadvantage students. Younger individuals may face insecurities related to continuing their education and to the access to higher education, fearing that changes in study routine might compromise the posterior insertion to the job market. Furthermore, the higher psychological vulnerability of the young population can be explained by their high access to alarming and distorted information via media and social networks.5,6 The usage of sleep medication was significantly associated with the three dimensions evaluated by DASS-21. These results show that the population with COVID-19 symptoms have presented sleep deprivation because of high levels of anxiety, depression, and stress. Also, it reflects worries that surround the aggravation of clinical state, as well as the difficulties to maintain a selfquarantine. 2,11 Chronic disease carriers were the group with highest frequency sign and symptoms of severe/extreme anxiety and depression. These patients are the risk group for COVID-19, which contributes to an intense fear of being contaminated by SARS-CoV-2, consequently, chronic disease carriers are more susceptible to develop psychiatric disorders. 6,23

The correlation that was found between the reduction or absence of physical exercises and leisure activities with the signals and symptoms for severe/extreme anxiety, depression and stress demonstrates the importance of being active during the pandemic. Higher levels of depression were identified in individuals that reported changes in daily routine in this pandemic. ${ }^{5}$ One possible explanation to the observed fact is that spending more time at home may increase the exposure to social media, which contains excessive information about the pandemic - including fake news and imprecise information - that can contribute to the augment of anxiety and fear. Because of this, authors have shown that the practice of physical exercises and leisure activities act as support measures for coping with problems during the period of social distance. 30 Also, these activities work as protective factors against psychiatric morbidities.

This study has some limitations. Aiming to optimizing the study time and sample, this study was conducted through an on-line questionnaire. Thus, the sample was limited to individuals with access to the internet and to social media, besides the majority of the participants were young.

Once this study was realized with COVID-19 symptomatic individuals, the results cannot be extended to the general population. However, the sample profile constitutes a differential in this study, since most of the studies had concentrated their efforts in the evaluation of the pandemic psychological repercussions in the general population.

Although some participants had taken the COVID-19 test, their results were not informed to the authors, therefore it was not possible to differentiate how many presented the positive or negative test among our sample of symptomatic individuals. The comparison of signals and symptoms of anxiety, depression, and stress between these 2 groups may be an objective for future studies.

According to WHO, 14 the testing for COVID-19 is a strategic tool for the public health problem. By testing, it is possible to identify and manage the COVID-19 new cases, reducing the sub-notification, which can make the scenario clear for authorities to develop strategies aiming at the reduction of virus transmissibility and social and economic impacts. Besides that, our study demonstrated that taking a COVID-19 test has constituted a protective factor against anxiety, depression and stress in the sample assessed. It is suggested that the test should be taken aiming at preventing the development of psychiatric morbidity in the COVID-19 symptomatic population.

The population symptomatic for COVID-19 consists of a vulnerable group to the development of significant levels of sign and symptoms of anxiety, depression and stress if compared to the general population.

Taking a COVID-19 test makes possible not only to settle down uncertainties, fantasies, and anxiety, but also to develop coping and caring strategies, including, if contaminated, a solicitation of a selfquarantine to the diagnosed patient with COVID-19 followed by the correct treatment of symptoms. The urgency to analyze the psychiatric morbidity 
frequency, their protective and risk factors in the COVID-19 symptomatic population reinforces the necessity to develop mental health strategies that involve the prevention and mitigation of psychological impact in such populations, as well as the treatment of acute cases.

\section{Author's contribution}

Conception and design of the research: Santos AC, Tenorio PJ, Barbosa EAS, Souza GFA, Souza GA, Praciano GAF, Maranhão LBB, Costa GOLP e Souza, ASR; Data collection: Santos AC, Souza GFA, Souza GA, Praciano GAF e Souza, ASR ; Data

\section{References}

1. WHO (Word Health Organization). Overview of public health and social measures in the context of COVID-19: interim guidance; 2020. Available from: https://apps.who.int/iris/rest/bitstreams/1278127/retrieve.

2. Brooks SK, Webster RK, Smith LE, Woodland L, Wessely $\mathrm{S}$, Greenberg N, et al. The psychological impact of quarantine and how to reduce it: rapid review of the evidence. Lancet. 2020; 395 (10227): 912-20.

3. Baumeister RF, Leary MR. The need to belong: Desire for interpersonal attachments as a fundamental human motivation. Psychol Bull. 1995; 117 (3): 497-529.

4. Kumar A, Nayar KR. Covid 19 and its mental health consequences. J Ment Heal. 2020; 0(0):1-2.

5. Ustun G. Determining depression and related factors in a society affected by COVID-19 pandemic. Int J Soc Psychiatry. 2020. Available from: http://journals.sagepub.com/doi/10.1177/00207640209388 07

6. Ozamiz-Etxebarria N, Dosil-Santamaria M, PicazaGorrochategui M, Idoiaga-Mondragon N. Stress, anxiety, and depression levels in the initial stage of the COVID-19 outbreak in a population sample in the northern Spain. Cad Saúde Pública. 2020; 36 (4): 1-9.

7. Weir K. Grief and COVID-19: mourning our bygone lives American Psychological Association. 2020. Available from: https://www.apa.org/news/apa/2020/04/grief-covid-19

8. Shigemura J, Ursano RJ, Morganstein JC, Kurosawa M, Benedek DM. Public responses to the novel 2019 coronavirus (2019-nCoV) in Japan: Mental health consequences and target populations. Psychiatry Clin Neurosci. 2020; 74 (4): 281-2.

9. Goyal K, Chauhan P, Chhikara K, Gupta P, Singh MP. Fear of COVID 2019: First suicidal case in India! Asian J Psychiatr. 2020; 49: 101989.

10. Chodkiewicz J, Talarowska M, Miniszewska J, Nawrocka N, Bilinski P. Alcohol Consumption Reported during the COVID-19 Pandemic: The Initial Stage. Int J Environ Res Public Health. 2020; 17 (13): 1-11.

11. Xiang Y-T, Yang Y, Li W, Zhang L, Zhang Q, Cheung T, et analysis and interpretation and manuscript writing: Santos AC, Tenorio PJ, Barbosa EAS, Souza GFA, Souza GA, Praciano GAF, Maranhão LBB, Costa GOLP e Souza, ASR; Statistical analysis: Souza GFA e Souza ASR; Critical review of the manuscript regarding important intellectual content: Santos AC, Tenorio PJ, Barbosa EAS, Souza GFA, Souza GA, Praciano GAF, Maranhão LBB, Costa GOLP e Souza, ASR. All authors approved the final version of the article.

al. Timely mental health care for the 2019 novel coronavirus outbreak is urgently needed. The Lancet Psychiatry. 2020;7(3):228-9.

12. Li W, Yang Y, Liu Z-H, Zhao Y-J, Zhang Q, Zhang L, et al. Progression of Mental Health Services during the COVID19 Outbreak in China. Int J Biol Sci. 2020; 16 (10): 1732-8.

13. Silva RM, Shavitt RG, Costa DL. Obsessive-compulsive disorder during the COVID-19 pandemic. Brazilian J Psychiatry. 2020; 00(00): 7316.

14. WHO (Word Health Organization). Laboratory testing strategy recommendations for COVID-19: interim guidance. 2020 .

15. Ministério da Saúde. Diretrizes para diagnóstico e tratamento da COVID-19. Ministério da Saúde. 2020;1:1-398. Available from: https://sbim.org.br/images/files/notastecnicas/ddt-covid-19-200407.pdf

16. Ministério da Saúde. Saúde passa a testar casos leves de Covid-19. 2020. Available from: https://www.saude.gov.br/noticias/agencia-saude/47113saude-passa-a-testar-100-dos-casos-leves-de-covid-19

17. Wilder-Smith A, Freedman DO. Isolation, quarantine, social distancing and community containment: pivotal role for old-style public health measures in the novel coronavirus (2019-nCoV) outbreak. J Travel Med. 2020; 27 (2): $1-4$.

18. Lovibond, S.H., Lovibond PF. Manual for the Depression Anxiety Stress Scales. fourth ed. Sydney: Psychology Foundation; 2004.

19. Vignola RCB, Tucci AM. Adaptation and validation of the depression, anxiety and stress scale (DASS) to Brazilian Portuguese. J Affect Disord. 2014; 155 (1): 104-9.

20. Patias ND, Machado WDL, Bandeira DR, Dell'Aglio DD. Depression Anxiety and Stress Scale (DASS-21) - Short Form: Adaptação e Validação para Adolescentes Brasileiros. Psico-USF. 2016; 21 (3): 459-69.

21. Horesh D, Brown AD. Traumatic stress in the age of Covid19: A call to close critical gaps and adapt to new realities. Psychol Trauma. 2020; 12 (4): 331-5. 
22. Salari N, Hosseinian-Far A, Jalali R, Vaisi-Raygani A Rasoulpoor S, Mohammadi M, et al. Prevalence of stress, anxiety, depression among the general population during the COVID-19 pandemic: a systematic review and metaanalysis. Global Health. 2020; 16 (1): 57.

23. Wang C, Pan R, Wan X, Tan Y, Xu L, Ho CS, et al Immediate Psychological Responses and Associated Factors during the Initial Stage of the 2019 Coronavirus Disease (COVID-19) Epidemic among the General Population in China. Int J Environ Res Public Health. 2020; 17 (5): 1729.

24. Lagier JC, Colson P, Tissot Dupont H, Salomon J, Doudier B, Aubry C, et al. Testing the repatriated for SARS-Cov2: Should laboratory-based quarantine replace traditional quarantine? Travel Med Infect Dis. 2020; 34 (January): 101624

25. Harper CA, Satchell LP, Fido D, Latzman RD. Functional Fear Predicts Public Health Compliance in the COVID-19 Pandemic. Int J Ment Health Addict. 2020; 44 (0): 1-21.
26. Colizzi M, Bortoletto R, Silvestri M, Mondini F, Puttini E, Cainelli $\mathrm{C}$, et al. Medically unexplained symptoms in the times of COVID-19 pandemic: a case-report. Brain Behav Immun Health. 2020 (5): 100073. Available from: https://doi.org/10.1016/j.bbih.2020.100073

27. WHO (Word Health Organization). "Immunity passports" in the context of COVID-19. 2020. Available from: https://www.who.int/news-room/commentaries/detail/.

28. Lim GY, Tam WW, Lu Y, Ho CS, Zhang MW, Ho RC. Prevalence of Depression in the Community from 30 Countries between 1994 and 2014. Sci Rep. 2018; 8 (1): 2861.

29. Rehman U, Shahnawaz MG, Khan NH, Kharshiing KD, Khursheed M, Gupta K, et al. Depression, Anxiety and Stress Among Indians in Times of Covid-19 Lockdown. Community Ment Health J. 2020. Available from: http://www.ncbi.nlm.nih.gov/pubmed/32577997

30. Jiloha R. COVID-19 and Mental Health. Epidemiol Int. 2020; 05 (01): 7-9.

Received on October 5, 2020

Approved on December 7, 2020 